\title{
Kepemimpinan Transformasional dalam Mewujudkan Budaya Madrasah Berkualitas di Madrasah Aliyah Istimewa Amanatul Ummah Pacet Mojokerto
}

\author{
Agung Dwi Bahtiar El Rizaq \\ Institut Agama Islam Negeri Madura, Pamekasan, Indonesia \\ elrizaq@iainmadura.ac.id
}

\begin{abstract}
Quality education as a major milestone in realizing human resources to survive in the midst of the globalization challenges. This study aims to interpret the principals transformational leadership style in building quality culture at the MA Istimewa (MAI) Amanatul Ummah Pacet Mojokerto. This study uses a qualitative method by descriptive approach. The primary and secondary data were analyzed using Miles and Huberman technique. The result of this study is the transformational leadership model applied at the Amanatul Ummah including; the implementation of leader grand idea as a reference for various programs and improving the quality of educator resources; then the madrasah culture formed through intracurricular activities that prioritize the quality of learning, extracurricular activities to explore the students talents and interests, implementation of madrasa culture to instil alkarimah character, and involve the community by asking suggestion. This study recommends to explore the integration of mu'adalah and formal education system learning in pesantren.
\end{abstract}

Keywords: Madrasa Culture; Transformational Leadership; Quality Education 


\begin{abstract}
Abstrak
Fokus Kajian ini menginterpretasi gaya kepemimpinan transformasional kepala madrasah dalam mewujudkan budaya madrasah berkualitas di MA Istimewa Amanatul Ummah Pacet Mojokerto. Kajian ini adalah penelitian kualitatif deskriptif. Data primer dan sekunder yang diperoleh dianalisis menggunakan teknis Miles and Huberman. Kajian ini menghasilkan temuan model kepemimpinan transformasional yang diterapkan di MA Istimewa Amanatul Ummah meliputi; perasamaan persepsi grand idea sebagai acuan berbagai program, peningkatan kualitas sumber daya pendidik, serta tahapan pengendalian berbagai program yang sistematis. Kemudian, budaya yang dibentuk untuk mewujudkan madrasah berkualitas meliputi kegiatan intrakurikuler yang mengedepankan kualitas pembelajaran, ekstrakurikuler untuk penggalian bakat dan minat peserta didik, implementasi budaya madrasah untuk mengarahkan individu memiliki akhlak al-karimah, serta pelibatan masyarakat dari berbagai lapisan sebagai sumber untuk mengetahui tantangan dan harapan. Kajian ini merekomendasikan untuk mendalami integrasi pembelajaran di pesantren dengan sistem mu'adalah dengan pendidikan formal.
\end{abstract}

Kata kunci: Budaya Madrasah, Kepemimpinan Transformasional, Pendidikan Berkualitas

\title{
A. Pendahuluan
}

Pendidikan yang berkualitas merupakan pondasi bagi kehidupan sosial (Idris et al. 2012), ujung tombak keberhasilan suatu negara (Fahmi, Yuwanita, and Faiza 2021), pembangunan berkelanjutan (Laurie et al. 2016), dan meningkatkan standar hidup individu (Akareem and Hossain 2016). Pendidikan merupakan investasi untuk menjamin perkembangan dan kelangsungan hidup sumber daya manusia (Saini 2017). Pendidikan sebagai sarana yang bertujuan menyiapkan kompetensi generasi muda agar mumpuni sebagai penerus estafet kepemimpinan sebuah negara (Wereszczyńska 2018).

Kualitas pendidikan dalam perspektif ini dipahami sebagai suatu tujuan yang meliputi seluruh aspek pendidikan (input, proses, dan output) sebagai bagian penting dari agenda pendidikan global (UNESCO, 2014). Dalam meningkatkan kualitas pendidikan tersebut, berbagai intervensi pendidikan penting untuk dilakukan (Garira 2020). Berbagai bentuk intervensi dibangun dalam suatu mekanisme sistem pendidikan secara menyeluruh untuk menjamin kestabilan kualitas pendidikan (Garira, Howie, and Plomp 2020). Wujud intervensi untuk menjamin kualitas pendidikan meliputi kelengkapan fasilitas sekolah, kemampuan manajerial dan cara mengajar, serta pengembangan kompetensi pendidik (Dawabsheh, Mustanir, and Jermsittiparsert 2020). 
Kualitas institusi pendidikan yang baik ditentukan oleh kesatuan sistem yang baik, terdiri dari perencanaan, materi dan sistem tata kelola, serta disampaikan oleh guru dengan kualifikasi yang bermutu (Elvira 2021). Berbagai bentuk intervensi telah untuk meningkatkan kualitas pendidikan telah banyak dilakukan, salah satunya berupa peningkatan kompetensi staf melalui pelatihan bagi guru semakin marak diselenggarakan. Seperti langkah yang dilakukan Zimbabwe dalam mengejar kualitas pendidikannya dengan melaksanakan kebijakan kursus pendidikan guru nasional (Chivore, 1992). Implementasi program Instructional Lead Teachers (ILTs) yang dilaksanakan oleh pemerintah Amerika Serikat terbukti memberikan dampak instruksional kepada guru untuk meningkatkan keterampilan manajemen kelas dan prestasi siswa (Thomas et al. 2020). Kemudian kebijakan The Every Student Succeeds Act (ESSA) yang dilaksanakan beberapa negara bagian yang menitik beraktkan distribusi guru sesuai kompetensinya terbukti sangat efektif menumbuhkan kualitas pendidikan (Saultz et al. 2017).

Berikutnya, faktor kepemimpinan dan administrasi di sekolah memegang peran penting dalam meningkatkan kualitas pendidikan. Kepemimpinan dan administrasi yang baik sangat diperlukan untuk mencapai efisiensi organisasi (Bush et al. 2021). Sikap pemimpin sekolah yang inovatif merupakan pendorong dan arahan dalam proses pendidikan. Pemimpin sekolah yang fokus pada target meningkatnya kualitas pembelajaran dan profesionalisme guru cenderung menghasilkan output berupa efisiensi dan efektivitas pembelajaran (Bush 2018).

Berbagai negara melakukan intervensi kepada kepala sekolah untuk menjamin kualitas pendidikan. Jerman melakukan pelatihan rutin dan supervisi kepada kepala sekolah untuk meningkatkan kapasitas dan profesionalisme peran agar memahami perkembangan kondisi dan tantangan zaman (Tulowitzki 2019). Berikutnya, pelatihan yang dilakukan oleh pemerintah Spanyol melalui koordinasi pedagogis dan gaya kepemimpinan memainkan peran kunci dalam hal membentuk iklim sekolah yang menumbuhkan kualitas dan profesionalisme guru (García-Martínez et al. 2020). Hal selaras dilakukan oleh Swedia, pelatihan kepada kepala sekolah melalui pendampingan dan praktik nyata memberikan dampak positif pada meningkatnya profesionalisme dan kualitas sekolah (Liljenberg and Wrethander 2020).

Beberapa manfaat dari pelatihan dan pengembangan kompetensi kepala sekolah dapat menunjang gaya kepemimpinan transformasional yang terbukti mampu meningkatkan kinerja manajerial pendidikan (Anderson 2017). Kepemimpinan transformasional berdampak pada meningkatnya motivasi dan kinerja guru yang secara simultan mengoptimalkan kualitas pendidikan (Andriani, Kesumawati, and Kristiawan 2018). Kepemimpinan transformasional menciptakan suasana kerja menjadi lebih 
bergairah dan membangun kepuasan pekerja maupun kualitas pembelajaran (Boamah et al. 2018). Lebih jauh, kepemimpinan transformasional mampu membangun ikatan psikologis sebagai kesatuan bagian dari institusi dan menurunkan keinginan untuk berpinah ke institusi yang lain (Chen and Wu 2017).

Paham kepemimpinan transformasional menjadi solusi untuk mencapai pendidikan yang berkualitas. Pemimpin yang memiliki sikap kepemimpinan transformasional berdampak positif pada inovasi dan keberhasilan implementasi program di sebuah institusi (Farahnak et al. 2019). Budaya madrsah merupakan wujud nyata implementasi program yang telah di jalankan. Oleh karena itu, dipandang penting untuk mengkaji budaya madrasah yang dikembangkan di sebuah lembaga pendidikan sebagai cerminan wujud kepemimpinan transformasional.

Pada sisi yang lain, madrasah sebagai lembaga pendidikan Islam telah terbukti berperan penting dalam setiap tahapan pembangunan dan kemajuan bangsa yang saat ini didominasi $91 \%$ dari yayasan/ Swasta dinilai perlu adanya perbaikan dan peningkatan kualitas (Maskur 2017). Kondisi tersebut umumnya terjadi karena pendanaan yang kurang memadai, terbatasnya fasilitas, serta kompetensi pendidik yang belum maksimal (Maulana, Dian, and Jahari 2019). Selain itu, keterbatasan kompetensi manajerial pimpinan lembaga menjadi penghambat untuk melakukan efisiensi administrasi dan inovasi terkait progam unggulan (Kristiawan and Asvio 2018).

Pada kondisi berbeda, Madrasah Aliyah Istimewa (MAI) Amanatul Ummah Pacet Mojokerto terbukti menjadi Madrasah unggulan. Beberapa indikator tersebut ditunjukkan oleh manajemen pembiayaan pendidikan di MAI Amanatul Ummah telah dilaksanakan sesuai proses accounting dan auditing (Mujab and Nurhikmahyanti 2012). Implementasi manajemen di lembaga ini juga telah meliputi tahapan perencanaan, pengorganisasian, motivasi, pengawasan dan evaluasi (Putri 2018). Berikutnya kualitas pelayanan akademik yang optimal terbukti meningkatkan antusiasme siswa baru di madrasah ini (Azkiyah, Kartiko, and Zuana 2020).

Berikutnya, selain sistem yang diterapkan telah teruji, bukti nyata keunggulan MAI adalah diperolehnya berbagai kejuaraan baik nasional maupun internasional. Berikutnya, rata-rata sebanyak 92\% lulusan MAI diterima pada berbagai lembaga tinggi pendidikan ternama baik dalam dan luar negeri. Kemudian, sebanyak $45 \%$ alumni diterima pada jalur prestasi tanpa tes pada perguruan tinggi kenamaan. Selanjutnya, para alumni terbaik diberikan kesempatan untuk mengabdi menjadi pendidik untuk mengamalkan pengetahuan yang telah diterimanya serta memberikan inspirasi bagi peserta didik. 
Berbagai studi telah menjelaskan pengaruh kepemimpinan transformasional dalam meningkatkan kualitas institusi. Seperti hasil kajian (Nugroho et al. 2020) yang menunjukkan meningkatnya motivasi dan suasana bekerja karyawan setelah implementasi kepemimpinan transformasional. Karakteristik kepemimpinan transformasional yang dimiliki kepala sekolah di Malaysia memiliki korelasi positif dan signifikan dalam menumbuhkan budaya sekolah (Veeriah et al. 2017). Kemudian, keberhasilan implementasi kepemimpinan transformasional bergantung juga pada kombinasi iklim di sekolah yang mengarahkan budaya inovasi warga sekolah (Wang 2019).

Berbagai penelitian terdahulu telah menjelaskan manfaat kepemimpinan transformasional dalam membangun budaya sekolah. Namun dari berbagai penelitian tersebut belum ditemukan kajian yang dilakukan untuk mewujudkan budaya madrasah yang berkualitas. Sehingga, dipandang menarik untuk mengkaji budaya yang dibangun di Madrasah Aliyah Istimewa Amanatul Ummah sebagai salah satu lembaga yang menorehkan berbagai prestasi baik nasional maupun internasional. Berbagai prestasi tersebut tidak hanya dihasilkan oleh peserta didik, namun para pendidik juga mendapatkan berbagai prestasi dan penghargaan. Segala hasil prestasi dan penghargaan yang didapatkan tersebut tidak terlepas dari gaya kepemimpinan transformasional sang pemimpin yang menumbuhkan iklim akademik yang baik.

Kajian penelitian kualitatif deskriptif ini fokus pada interpretasi tipe kepemimpinan transformasional kepala madrasah dalam membangun budaya madrasah berkualitas di MA Istimewa Amanatul Ummah Pacet Mojokerto. Data dikumpulkan dengan teknik observasi, wawancara dan dokumentasi meliputi; a) Data primer berupa manajemen MA Istimewa Amanatul Ummah, serta b) Data sekunder berupa sistem pendidikan secara keseluruhan serta pengembangan program yang dilaksanakan. Analisis data mengacu pada Miles and Huberman yang berpandangan penelitian kualitatif dilakukan secara interaktif secara terus menerus melalui tahapan analisis data; reduksi, display, dan pengambilan keputusan atau verifikasi.

\section{B. Pembahasan}

\section{Kepemimpinan Transformasional dan Kualitas Pendidikan}

Kualitas pendidikan di suatu lembaga tidak bisa dilepaskan dari peran pemegang kebijakan selaku manajerial. Gaya kepemimpimpinan di MA Istimewa Amanatul Ummah terbukti sangat transformasional. Hal tersebut dibuktikan dengan berbagai penghargaan yang diterima baik oleh lembaga, pendidik, serta peserta didik. Seluruh penghargaan tersebut merupakan akumulasi dari terwujudnya program-program yang 
telah direncanakan. Model kepemimpinan transformasional yang diterapkan di MA Istimewa Amanatul Ummah diawali grand idea pengasuh pesantren sebagai pengarah haluan madrasah yang diwujudkan dalam visi, misi, dasar pendirian, serta tujuan yang akan dicapai. Pesan utama sang pengasuh adalah "Jadilah pendidik baik, atau tidak sama sekali” (KH. Asep Saifuddin Chalim).

Nasehat tersebut nyata dilaksanakan oleh segenap civitas akademika MA Istimewa Amanatul Ummah. Sebagai ujung tombak pemegang kebijakan, kepala madrasah senantiasa melaksanakan rapat pra kerja untuk merancang desain dan kegiatan di madrasah, yang kemudian dilakukan finalisasi pada rapat kerja. Program awal yang dilakukan sebelum mengembangkan kompetensi yang dimiliki peserta didik adalah melalui seleksi awal, seperti penjelasan Dr. Mauhibur Rohman, Lc., MRIKH (Kepala Madrasah);

“....sebelum membina peserta didik untuk menjadi insan berkualitas, MA Istimewa Amanatul Ummah menerapkan sistem penerimaan peserta didik baru berdasar dua jalur, yakni prestasi ataupun tes. Pengelola madrasah memiliki standar kualifikasi khusus yang harus dimiliki peserta didik untuk di terima, yakni prestasi akademik maupun non akademik yang menonjol dengan level minimal kompetisi tingkat kabupaten/kota..."

Penjelasan tersebut menegaskan bahwa peserta didik yang dapat bergabung di MAI Amanatul Ummah adalah individu yang memiliki prestasi atau standar kualifikasi tertentu. Input yang berkualitas tersebut merupakan modal awal yang dimiliki madrasah untuk mengarahkan peserta didik sesuai bakat dan minatnya. Input yang baik tersebut akan diarahkan sesuai potensi yang dimilikinya apabila pendidik di MAI memiliki kompetensi yang baik. Dalam hal kualifikasi pendidik, Yuniarto Suwardi, M.Si selaku Wakil Koordinator MAI menjelaskan sebagai berikut;

“...seleksi pengajar di MAI cukup ketat, hanya lulusan perguruan tinggi dengan akreditasi unggul yang dapat melamar. Kualifikasi lainnya adalah memiliki IPK minimal 3,00 dan linier antara jurusan dan mata pelajaran yang dilamar, mampu berbahasa Arab atau bahasa Inggris, lulusan luar negeri, serta memberikan pertimbangan khusus bagi alumni peraih beasiswa yang mengabdi..."

Ketatnya seleksi yang dilaksanakan oleh internal MAI memberikan dampak pada kualitas sumber daya manusia yang mumpuni dan berkualitas. Kondisi tersebut berdampak langsung pada meningkatnya kualitas dan hasil pembelajaran. Kemampuan berbahada Arab atau Inggris menambah khazanah bagi pendidik untuk mengikuti eveneven Internasional, baik terkait perlombaan maupun peningkatan kompetensinya. Kemampuan berbahasa tersebut juga mendukung penyampaian materi dengan bahasa asing untuk meningkatkan keterampilan berbahasa peserta didik. 
Peningkatan kompetensi pendidik dilaksanakan dengan pendelegasian untuk mendalami bakat dan minat yang dimilikinya sebagai sarana mendalami kompetensi baik melalui pelatihan, training of trainer agar dapat berimbas bagi sesama pendidik dan kualitas pengajaran. Hal tersebut merupakan kunci utama dalam membentuk institusi yang berisi sumber daya kompeten (Rembangy 2010). Hal tersebut senada dengan penjelasan Imas Masitho, S.Si (Wakil Kepala bidang Kurikulum);

“....peningkatan kompetensi pendidik rutin kami lakukan, mulai dengan mendatangkan praktisi pendidikan dari luar, pembahasan isu terkini terkait pendidikan, maupun mengirim pendidik untuk mengikuti pelatihan di luar lembaga..."

Penjelasan tersebut menunjukkan bahwa peningkatan kompetensi pendidik dilaksanakan secara intens oleh lembaga. Pendidik yang kompeten adalah kunci utama terlaksananya proses pembelajaran yang berkualitas. Pengembangan kompetensi diperlukan guna meminimalisir permasalahan yang ada selama pembelajaran agar berjalan sesuai harapan (sudrajat 2020). Selai itu, konsistensi monitoring dan evaluasi adalah sarana kontrol kualitas pembelajaran, sesuai dengan penjelasan Dr. Mauhibur Rohman, Lc., MRIKH (Kepala Madrasah);

“....selain itu, monitoring dan evaluasi senantiasa kami laksanakan guna menjaga kualitas lembaga, baik terkait pembelajaran maupun pendampingan dan pengarahan bakat dan minta yang dimiliki peserta didik melalui; 1) pengawasan, 2) evaluasi, 3) tata tertib, dan 4) pemantauan mutu lulusan ..."

Pengawasan dilakukan oleh koordinator umum dan wakil koordinator sesuai tanggung jawabnya masing-masing untuk mengontrol target yang telah ditetapkan pada rapat kerja. Kemudian evaluasi dilakukan baik dalam mingguan oleh fungsionaris dan wali kelas, evaluasi bulanan oleh koordinator dan tim divisi masing-masing, serta evaluasi berdasarkan kritik dan saran oleh warga madrasah dan masyarakat. Pengendalian tata tertib dilakukan bagi pendidik dan peserta didik agar seluruh warga madrasah memiliki akhlak al-karimah yang terdiri dari larangan dan sanksi. Berikutnya pemantauan mutu lulusan dilakukan untuk menelusuri jejak alumni dan progres masingmasing alumni dalam menelusuri tahap kehidupan berikutnya untuk senantiasa menjalin silaturrahmi dengan madrasah.

\section{Budaya Madrasah dalam Meningkatkan Kualitas Pendidikan}

Bagian ini menggali program sekolah yang terkait dengan pendidikan berkualitas melalui kegiatan intrakurikuler, kegiatan ekstrakurikuler, membangun budaya sekolah dan berbagai kegiatan partisipasi masyarakat. 


\section{a. Kegiatan Intrakurikuler}

Implementasi kegiatan intrakurikuler yang diterapkan di MA Istimewa Amanatul Ummah merupakan perpaduan kurikulum nasional (Kurikulum 2013 Revisi) dan kurikulum Al-Azhar Cairo Mesir. Wujud kegiatan intrakurikuler yang diterapkan adalah sekolah formal dan sekolah muadalah. Bahasa pengantar yang digunakan pada sekolah formal umumnya menggunakan bahasa inggris. Serta memiliki program unggulan pembelajaran ulang (dauroh). Pembelajaran dauroh khusus diterapkan pada kelas akhir yang dimaksudkan untuk mendalami kembali materi pembelajaran pada jenjang awal. Untuk mengetahui kemampuan masing-masing individu terkait aktifitas intrakurikuler dilakukan melalui beberapa kegiatan, seperti penjelasan Imas Masitho, S.Si (Wakil Kepala bidang Kurikulum);

“...program Evaluasi MAI meliputi: ujian tiap semester, ulangan harian berbentuk bahasa Arab maupun Inggris, muadalah setara dengan Universitas Al Azhar Mesir bagi semester V, Ujian TOEFL dengan pendampingan AMINEF, serta rapat program kerja tahunan..."

Secara umum, madrasah ini memiliki pandangan sebagai pesantren komperhensif dengan perpaudan pendidikan pesantren tradisional dan modern serta implementasi berbagai model pembelajaran kekinian yang inovatif (Rizaq and Sarmini 2021). Kombinasi tersebut menjadikan peserta didik memiliki kualifikasi khusus dan terarah pada masing-masing bakat dan minatnya. Hal tersebut didukung dengan penelitian yang menyimpulkan kombinasi kematangan spiritual dan intelegensi melahirkan insan yang berkualitas (Langmann 2021). Penjelasan tersebut sesuai dengan praktik MAI seperti uaraian Yuniarto Suwardi, M.Si selaku Wakil Koordinator MAI;

“...manajemen MAI didukung dengan terintegrasinya sistem pesantren dan madrasah dibawah pengasuhan Kiai Langsung guna menjamin Hubungan yang baik antara civitas akademika dan alumni Madrasah, serta kuatnya kompetensi pengetahuan dan spiritual peserta didik..."

Selain itu, untuk menunjang kemampuan peserta didik untuk melanjutkan pada jenjang berikutnya, implementasi metode drill dan latihan soal pada jenjang akhir bertujuan untuk Penguatan dan pendalaman pengetahuan bagi jenjang akhir dilakukan setiap pekan. Hal tersebut dijelaskan oleh Dr. Mauhibur Rohman, Lc., MRIKH (Kepala Madrasah);

“...untuk menjamin lulusan MAI diterima di perguruan tinggi ternama, kami melaksanakan program drilling setiap pekan untuk membiasakan peserta didik jenjang akhir mengerjakan latihan soal..."

Metode drilling merupakan cara untuk membiasakan peserta didik mengerjakan soal-soal. Pembiasaan tersebut sesuai dengan hasil kajian yang menjelaskan tentang 
meningkatnya hasil belajar siswa dilakukan dengan penggunaan metode drilling sesuai karakteristik dan kebutuhan peserta didik (Nasution 2012). Pembiasaan tersebut merupakan langkah unggulan yang memiliki bukti nyata sebanyak $95 \%$ alumni diterima diberbagai perguruan tinggi unggulan baik nasional maupun internasional.

\section{b. Kegiatan Ekstrakurikuler}

Kegiatan ekstrakurikuler di MA Istimewa Amanatul Ummah mendukung penelusuran bakat dan minat peserta didik. Berbagai kegiatan ekstrakurikuler yang disediakan adalah; Jurnalistik, Banjari, Kaligrafi, Qiro'ah Pramuka, Hadrah dan Paduan Suara. Seluruh detail kegiatan tersebut sebagai berikut;

Tabel 1. Ekstrakurikuler di MA Istimewa Amanatul Ummah

\begin{tabular}{|c|c|c|}
\hline No. & $\begin{array}{c}\text { Kegiatan } \\
\text { Ekstra }\end{array}$ & Keterangan \\
\hline 1. & Pramuka & $\begin{array}{l}\text { Pramuka sebagai kegiatan menyatu dengan alam } \\
\text { dilakukan di area pondok pesantren. Kegiatan ini juga } \\
\text { mendukung kreatifitas, kekompakan, dan kemandirian } \\
\text { peserta didik. }\end{array}$ \\
\hline 2. & Jurnalistik & $\begin{array}{l}\text { Jurnalistik dilakukan untuk menyalurkan bakat fotografi } \\
\text { dan news anchor peserta didik guna menggali ide } \\
\text { kratifitas dan menemukan ide baru yang inovatif terkait } \\
\text { tulis menulis. }\end{array}$ \\
\hline 3. & Banjari & $\begin{array}{l}\text { Banjari merupakan salah satu kegiatan yangjuga diminati } \\
\text { oleh peserta didik yang gemar musik Islami. Banjari } \\
\text { sebagai pengisi kegiatan rutin di pondok pesantren. }\end{array}$ \\
\hline 4. & Kaligrafi & $\begin{array}{l}\text { Kaligrafi sebagai salah satu kegiatan bagi peserta didik } \\
\text { yang memiliki kreatifitas tinggi terkait membuat karya } \\
\text { keindahan khat tulisan arab. Para kaligrafer yang sudah } \\
\text { mahir sering didelegasikan mengikuti lomba dan menjadi } \\
\text { juara. }\end{array}$ \\
\hline 5. & Qiro'ah & $\begin{array}{l}\text { Qiro'ah menjadi alternatif ekstrakurikuler yang diminati } \\
\text { peserta didik yang memiliki suara merdu dalam } \\
\text { melantunkan ayat Al-Qur'an. Peserta didik yang mahir } \\
\text { Qiro'ah sering menjadi pengisi acara dan didelegasikan } \\
\text { mengikuti perlombaan MTQ yang keluar menjadi juara. }\end{array}$ \\
\hline 6. & Hadrah & $\begin{array}{l}\text { Hadrah menjadi kegiatan yang memiliki peminat tidak } \\
\text { banyak karena kegiatan ini membutuhkan waktu yang } \\
\text { banyak dan ketekunan. }\end{array}$ \\
\hline 7. & $\begin{array}{l}\text { Paduan } \\
\text { suara }\end{array}$ & $\begin{array}{l}\text { Paduan suara sebagai ekstrakurikuler yang cukup } \\
\text { diminati, namun haanya peserta didik dengan kualitas } \\
\text { tertentu yang dapat bergabung dalam ekstrakurikuler ini. }\end{array}$ \\
\hline
\end{tabular}


Tidak hanya meliputi kegiatan pengembangan bakat dan minat, tapi disediakan alokasi bagi peserta didik yang menginginkan pemantapan materi. Kelas-kelas olimpiade juga disediakan bagi peserta didik yang memiliki kualifikasi tertentu sesuai bidang keahliannya untuk semakin menggali potensi yang dimiliki. Hal tersebut diuraikan oleh koordinator olimpiade, Faldi;

“...kegiatan ekstrakurikuler tidak hanya terbatas pada minat peserta didik pada kegiatan non kurikuler, namun juga mengarahkan peserta didik berkemampuan kurikuler diatas kondisi umum. Peserta didik tersebut dikelompokkan pada program olimpiade yang mengarahkan pendalaman dan penguasaan suatu mata pelajaran dengan target menjadi delegasi olimpiade dan membawa nama harum lembaga..."

Penguatan bakat dan minat tersebut tidak hanya dilakukan untuk menggali potensi yang dimiliki peserta didik, namun juga disiapkan untuk mengikuti kompetisi dalam dan luar negeri. Sehingga kegiatan ekstrakurikuler tersebut juga menjadi sarana menyebar luaskan kompetensi yang dimiliki peserta didik (El Rizaq and Sarmini 2020). Hal tersebut senada dengan pandangan bahwa kecakapan peserta didik pada bidang non intrakurikuler merupakan modal untuk menghadapi tantangan zama yang semakin membutuhkan keahlian (Keser, Akar, and Yildirim 2011).

\section{c. Implementasi Budaya Madrasah}

Budaya madrasah dapat memotivasi siswa untuk berbuat lebih baik dengan memberikan aturan dan peraturan yang sesuai dengan visi sekolah (Ravindran 2018). Kondisi tersebut dapat menjadi dasar bagi madrasah untuk membuat regulasi sesuai karakter lembaga untuk mengantarkan peserta didik menjadi insan berkualitas. Implementasi budaya madrasah menjadi dasar utama membentuk karakter peserta didik sesuai harapan visi dan misi lembaga.

Budaya madrasah yang dibentuk di MA Istimewa Amanatul Ummah diawali dengan rutinitas apel pagi yang berisi penguatan kompetensi spiritual dan motivasi yang langsung dipimpin oleh pengelola madrasah. Hal tersebut menjadi pembiasaan peserta didik untuk mendapatkan motivasi setiap akan memulai pembelajaran. Harapannya peserta didik menjadi pribadi yang memiliki keinginan besar untuk belajar dan berkembang menjadi pribadi berkualitas. Penjelasan mengenai implementasi budaya madrasah yang dibangun diuraikan oleh Imas Masitho, S.Si (Wakil Kepala bidang Kurikulum);

“...budaya utama yang kami bangun adalah pendidikan karakter ala pesantren melalui kesungguhan belajar, serta keikhlasan pendidik dalam mendampingi dan membimbing peserta didik. Metode takrir (repitisi) dimodelkan menjadi sistem dauroh hingga para murid benar-benar menguasai ilmu merupakan wujdu nyata kesungguhan peserta didik. Kemudian kesungguhan pendidik dalam membimbing peserta didik sejak 
awal hingga masuk perguruan tinggi pilhan merupakan impian yang terwujud seluruh pihak Yayasan lembaga...”

Berikutnya, pendidik yang berkualitas menjadi orang tua pengganti di madrasah. Pendidik tidak hanya sebagai pengajar, namun juga membimbing dan mendampingi berbagai aktifitas peserta didik. Peniadaan batas antara pendidik dengan peserta didik sangat kental dirasakan tanpa mengurangi wujud hormat kepada pendidik. Dalam praktik pembelajaran di kelas, pendidik selalui memberikan penjelasan yang terinci serta contoh nyata yang berkaitan erat dengan fenomena kehidupan peserta didik.

\section{d. Peran Serta Masyarakat}

Pelibatan masyarakat merupakan cara untuk membentuk program tepat sasaran sesuai kebutuhan dan kondisi masyarakat. Pelibatan tersebut memberikan kontribusi pada saran untuk memajukan madrasah (Ravindran 2018). Wujud nyata yang dilakukan lembaga adalah seperti penjelasan Yuniarto Suwardi, M.Si selaku Wakil Koordinator MAI berikut;

“...implementasi peran serta masyarakat yang dilakukan di MA Istimewa Amanatul Ummah adalah; a) memberikan kesempatan bagi wali murid ataupun masyarakat umum untuk memberikan saran, b) Pelibatan lain yang dilakukan adalah mengajak pihak-pihak terkait seperti pakar dari perguruan tinggi untuk memberikan sumbangsih dalam menyusun standar mutu pendidikan bagi madrasah, c) pengelola madrasah senantiasa proaktif terhadap perubahan yang menyangkut kualitas lembaga..."

Peran serta masyarakat dibedakan pada dua hal, wali murid atau peran masyarakat secara umum. Wali murid dilibatkan dengan adanya komunikasi khusus pada wali murid yang memegang amanah strategis di pemerintahan/tokoh selaku pemberi informasi kebutuhan masyakat. Atau peran masyarakat secara umum dilakukan dengan jajak pendapat mengenai masukan dan saran guna membangun kualitas pendidikan di MAI semakin meningkat.

\section{Simpulan}

Kajian ini menyimpulkan gaya kepemimpinan memegang peran penting dalam menjamin sebuah institusi pendidikan berkualitas. Model kepemimpinan transformasional yang diterapkan di MAI Amanatul Ummah meliputi beberapa hal; kualitas input peserta didik berdasarkan prestasi atau standar kualifikasi tertentu, terlaksananya peningkatan kompetensi pendidik, serta pengawasan dilakukan oleh koordinator mengenai seluruh program yang sedang berjalan. Kemudian, budaya madrasah yang dibentuk untuk mewujudkan lembaga yang berkualitas meliputi kegiatan intrakurikuler yang mengedepankan kualitas pembelajaran, ekstrakurikuler yang mengarahkan penggalian bakat dan minat peserta didik, implementasi budaya madrasah 
yang mengarahkan individu memiliki akhlak al-karimah, serta pelibatan masyarakat dari berbagai lapisan sebagai sumber untuk mengetahui tantangan dan harapan.

\section{DAFTAR PUSTAKA}

Akareem, Husain Salilul, and Syed Shahadat Hossain. 2016. "Determinants of Education Quality: What Makes Students' Perception Different?" Open Review of Educational Research 3(1): 52-67. https://www.tandfonline.com/doi/abs/10.1080/23265507.2016.1155167 (October 1, 2021).

Anderson, Matthew. 2017. "Transformational Leadership in Education: A Review of Existing Literature." International Social Science Review 93(1). https://digitalcommons.northgeorgia.edu/issr/vol93/iss1/4 (October 6, 2021).

Andriani, Septi, Nila Kesumawati, and Muhammad Kristiawan. 2018. "The Influence of the Transformational Leadership and Work Motivation on Teachers Performance." International Journal of Scientific and Technology Research 7(7): 19-29.

Azkiyah, Zahrotul, Ari Kartiko, and Muhammad Mujtaba Mitra Zuana. 2020. "PENGARUH KUALITAS PELAYANAN AKADEMIK DAN PROMOSI TERHADAP MINAT SISWA BARU DI MADRASAH." Nidhomul Haq : Jurnal Manajemen Pendidikan Islam 5(2): 290-303. https://ejournal.ikhac.ac.id/index.php/nidhomulhaq/article/view/538 (October 21, 2021).

Boamah, Sheila A., Heather K. Spence Laschinger, Carol Wong, and Sean Clarke. 2018. "Effect of Transformational Leadership on Job Satisfaction and Patient Safety Outcomes." Nursing Outlook 66(2): 180-89.

Bush, Tony. 2018. "Prescribing Distributed Leadership: Is This a Contradiction?" Educational Management Administration \& Leadership 46(4): 535-37. https://journals.sagepub.com/doi/full/10.1177/1741143218768403 (October 4, 2021).

. 2021. "Ensuring Acceptability and Feasibility: The Challenges of Educational Policy Reform in Malaysia." Educational Management Administration \& Leadership 2(2): 32. https://www.tandfonline.com/doi/abs/10.1080/15700763.2021.1933063 (October 4, 2021).

Chen, Tso Jen, and Chi Min Wu. 2017. "Improving the Turnover Intention of Tourist Hotel Employees: Transformational Leadership, Leader-Member Exchange, and Psychological Contract Breach." International Journal of Contemporary Hospitality Management 29(7): 1914-36.

Dawabsheh, Mohammad, Kittisak Mustanir, and Kittisak Jermsittiparsert. 2020. "School Facilities as a Potential Predictor of Engineering Education Quality: Mediating Role of Teaching Proficiency and Professional Development." TEST Engineering \& Management 82(January): $3511-21$. 
http://www.testmagzine.biz/index.php/testmagzine/article/view/1417.

Elvira. 2021. "Faktor Penyebab Rendahnya Kualitas Pendidikan Dan Cara Mengatasinya ( Studi Pada: Sekolah Dasar Di Desa Tonggolobibi ) Factors Causing the Low Quality of Education and How to Overcome It ( Study on: Elementary School in Tonggolobibi Village )." IQRA: Jurnal Ilmu Kependidikan dan Keislaman 16(2): 93-98.

Fahmi, Ahmad Khoirur Rijal, Ary Yuwanita, and Dwi Eni Nur Faiza. 2021. "Principal Transformational Leadership in Improving Teacher and School Staff Performance." International Research-Based Education Journal 3(1): 22-27. http://journal2.um.ac.id/index.php/irbej/article/view/19022 (October 1, 2021).

Farahnak, Lauren R., Mark G. Ehrhart, Elisa M. Torres, and Gregory A. Aarons. 2019. "The Influence of Transformational Leadership and Leader Attitudes on Subordinate Attitudes and Implementation Success:" https://doi.org/10.1177/1548051818824529 27(1): 98-111. https://journals.sagepub.com/doi/full/10.1177/1548051818824529 (October 14, 2021).

García-Martínez, Inmaculada, Pedro J. Arrifano Tadeu, Miguel Pérez-Ferra, and José Luis Ubago-Jiménez. 2020. "Building a Common Project by Promoting Pedagogical Coordination and Educational Leadership for School Improvement: A Structural Equation Model.” Social Sciences 2020, Vol. 9, Page 52 9(4): 52. https://www.mdpi.com/2076-0760/9/4/52/htm (October 4, 2021).

Garira, Elizabeth. 2020. "Needs Assessment for the Development of Educational Interventions to Improve Quality of Education: A Case of Zimbabwean Primary Schools." Social Sciences \& Humanities Open 2(1): 100020.

Garira, Elizabeth, Sarah Howie, and Tjeerd Plomp. 2020. "An Analysis of Quality of Education and Its Evaluation: A Case of Zimbabwean Primary Schools." South African Journal of Education 39(2). https://www.ajol.info/index.php/saje/article/view/187652 (October 4, 2021).

Idris, Fazilah et al. 2012. "The Role of Education in Shaping Youth's National Identity." Procedia - Social and Behavioral Sciences 59: 443-50. http://dx.doi.org/10.1016/j.sbspro.2012.09.299.

Keser, Filiz, Hanife Akar, and Ali Yildirim. 2011. "The Role of Extracurricular Activities in Active Citizenship Education." http://dx.doi.org/10.1080/00220272.2011.591433 83(6): https://www.tandfonline.com/doi/abs/10.1080/00220272.2011.591433 (September 30, 2021).

Kristiawan, Muhammad, and Nova Asvio. 2018. "Pengelolaan Administrasi Madrasah Tsanawiyah Negeri Dalam Meningkatkan Kualitas Pendidikan Madrasah.” Kelola: Jurnal Manajemen Pendidikan 56-95. https://ejournal.uksw.edu/kelola/article/view/1249 (October 21, 2021). 
Langmann, Elisabet. 2021. "Tolerance and Education.” Oxford Research Encyclopedia of Education. https://oxfordre.com/education/view/10.1093/acrefore/9780190264093.001.0001/a crefore-9780190264093-e-1512 (September 30, 2021).

Laurie, Robert, Yuko Nonoyama-Tarumi, Rosalyn Mckeown, and Charles Hopkins. 2016. "Contributions of Education for Sustainable Development (ESD) to Quality Education: A Synthesis of Research:" http://dx.doi.org/10.1177/0973408216661442 10(2): 226-42. https://journals.sagepub.com/doi/full/10.1177/0973408216661442 (October 1, 2021).

Liljenberg, Mette, and Marie Wrethander. 2020. "Leadership for School Improvement Linking Learning to Leading over Time." https://doi.org/10.1080/19415257.2020.1752288.

https://www.tandfonline.com/doi/abs/10.1080/19415257.2020.1752288 (October 4, 2021).

Maskur, Muhammad. 2017. "EKSISTENSI DAN ESENSI PENDIDIKAN MADRASAH DI INDONESIA." TERAMPIL: Jurnal Pendidikan dan Pembelajaran Dasar 4(1): 101-19. http://ejournal.radenintan.ac.id/index.php/terampil/article/view/1807 (October 21, 2021).

Maulana, Agung, Dian Dian, and Jaja Jahari. 2019. "Implementasi Manajemen Mutu Pendidikan Di Madrasah Swasta." AL MA'ARIEF : Jurnal Pendidikan Sosial dan Budaya 1(2): 89-96. https://ejurnal.iainpare.ac.id/index.php/ALMAARIEF/article/view/1109 (October 21, 2021).

Mujab, Muhammad Saiful, and Desi Nurhikmahyanti. 2012. "Manajemen Pembiayaan Pendidikan Di MA Unggulan Amanatul Ummah Surabaya Untuk Mencapai Predikat Sekolah Unggulan Abstrak." Universitas Negeri Surabaya 1(1): 1-12.

Nasution, Mardiah Kalsum. 2012. "Penggunaan Metode Pembelajaran Dalam Peningkatan Hasil Belajar Siswa | Studia Didaktika." STUDIA DIDAKTIKA: Jurnal Ilmiah Bidang Pendidikan 11(1): 9-16. http://www.jurnal.uinbanten.ac.id/index.php/studiadidaktika/article/view/515 (October 21, 2021).

Nugroho, Yunianto Agung et al. 2020. "Transformational Leadership and Employees' Performances: The Mediating Role of Motivation and Work Environment." EduPsyCouns: Journal of Education, Psychology and Counseling 2(1): 438-60. https://ummaspul.e-journal.id/Edupsycouns/article/view/507 (November 9, 2021).

Putri, Intan Budiana. 2018. "MANAJEMEN MADRASAH BERTARAF INTERNASIONAL AMANATUL UMMAH PACET MOJOKERTO." DINAMIKA: Jurnal Kajian Pendidikan dan Keislaman 3(1): 87-96. https://ejournal.unwaha.ac.id/index.php/dinamika/article/view/227 (October 21, 
2021).

Ravindran, Latha. 2018. "The Effects of School Culture Impacting on the Process of Change." Redesigning Learning for Greater Social Impact: 141-47. https://link.springer.com/chapter/10.1007/978-981-10-4223-2_12 (September 30, 2021).

Rembangy, Musthofa. 2010. Pendidikan Transformatif Pergulatan Kritis Merumuskan Pendidikan Di Tengah Pusaran Arus Globalisasi. Yogyakarta: Teras.

El Rizaq, Agung Dwi Bahtiar, and Sarmini. 2020. "Integrasi Nilai Karakter Lokal Dalam Pengembangan Bahan Ajar IPS Untuk Meningkatkan Wawasan Kebangsaan Siswa.” Jurnal Teori dan Praksis Pembelajaran IPS 5(1): 19-27.

Rizaq, Agung Dwi Bahtiar El, and Sarmini Sarmini. 2021. "Secondary School Teachers and Learners Perspective for Future of Education Post COVID-19 Pandemic." Tadris: Jurnal Keguruan dan Ilmu Tarbiyah 6(1): 171-82. http://ejournal.radenintan.ac.id/index.php/tadris/article/view/8385 (September 10, 2021).

Saini, Alka. 2017. "EDUCATION FOR SUSTAINABLE DEVELOPMENT ( EDS ): A WAY TO ENSURE SUSTAINABLE FUTURE." RECENT EDUCATIONAL \& PSYCHOLOGICAL RESEARCHES 6(3): 145-49.

Saultz, Andrew et al. 2017. "Teacher Quality, Distribution, and Equity in ESSA:" https://doi.org/10.1177/105268461702700503 27(5): 652-74. https://journals.sagepub.com/doi/abs/10.1177/105268461702700503 (October 4, 2021).

sudrajat, jajat. 2020. "KOMPETENSI GURU DI MASA PANDEMI COVID-19." Jurnal Riset Ekonomi dan Bisnis 13(2): 100-110. https://journals.usm.ac.id/index.php/jreb/article/view/2434 (October 21, 2021).

Thomas, Maryam, Sunddip Panesar-Aguilar, Michelle McCraney, and Chris Cale. 2020. "Educational Instructional Lead Teachers Perceptions on Improving Teacher Quality.” American International Journal of Contemporary Research 10(2): 1-7.

Tulowitzki, Pierre. 2019. "Supporting Instructional Leadership and School Improvement? Reflections on School Supervision from a German Perspective." Journal of Educational Administration 57(5): 571-81.

Veeriah, Jeyasushma, Chua Yan Piaw, Siaw Yan Li, and Kazi Enamul Hoque. 2017. “Teachers' Perception On The Relationships Between Transformational Leadership And School Culture In Primary Cluster Schools." MALAYSIAN ONLINE JOURNAL OF EDUCATIONAL MANAGEMENT 5(4): 18-34. http://journal.kuis.edu.my/attarbawiy/wp-content/uploads/2020/12/1-16.pdf.

Wang, Shutao. 2019. "School Heads' Transformational Leadership and Students' Modernity: The Multiple Mediating Effects of School Climates." Asia Pacific Education Review 20(3): 329-41. https://link.springer.com/article/10.1007/s12564- 
019-09575-3 (November 9, 2021).

Wereszczyńska, Katarzyna. 2018. "Importance of and Need for Intercultural Education According to Students: Future Teachers." Polish Journal of Educational Studies 71(1): 212-28. 